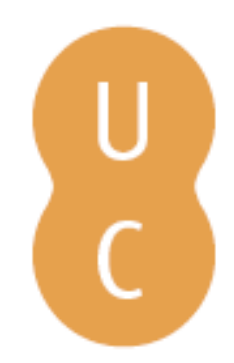

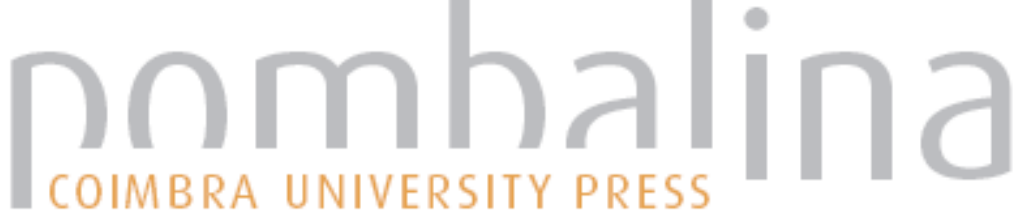

\section{Identificação em altas temperaturas}

Autor(es): $\quad$ Corte-Real, Ana; Oliveira, Carina; Vieira, Duarte Nuno

Publicado por: Imprensa da Universidade de Coimbra

URL

persistente: URI:http://hdl.handle.net/10316.2/38416

DOI: $\quad$ DOI:http://dx.doi.org/10.14195/978-989-26-0963-8_3

Accessed : $\quad$ 26-Apr-2023 15:09:05

A navegação consulta e descarregamento dos títulos inseridos nas Bibliotecas Digitais UC Digitalis, UC Pombalina e UC Impactum, pressupõem a aceitação plena e sem reservas dos Termos e Condições de Uso destas Bibliotecas Digitais, disponíveis em https://digitalis.uc.pt/pt-pt/termos.

Conforme exposto nos referidos Termos e Condições de Uso, o descarregamento de títulos de acesso restrito requer uma licença válida de autorização devendo o utilizador aceder ao(s) documento(s) a partir de um endereço de IP da instituição detentora da supramencionada licença.

Ao utilizador é apenas permitido o descarregamento para uso pessoal, pelo que o emprego do(s) título(s) descarregado(s) para outro fim, designadamente comercial, carece de autorização do respetivo autor ou editor da obra.

Na medida em que todas as obras da UC Digitalis se encontram protegidas pelo Código do Direito de Autor e Direitos Conexos e demais legislação aplicável, toda a cópia, parcial ou total, deste documento, nos casos em que é legalmente admitida, deverá conter ou fazer-se acompanhar por este aviso. 


\section{IDENTIFICAÇÃO EM MEDICINA DENTÁRIA FORENSE}

ANA CORTE-REAL DUARTE NUNO VIEIRA COORDENAÇÃO 
Capítulo III

\title{
Identificação em altas temperaturas
}

\begin{abstract}
Altas Temperaturas
Aspetos históricos da identificação de cadáveres

e/ou restos biológicos queimados

O corpo queimado versus carbonizado

- lesões peri mortem - o exame

Comportamento dos tecidos mineralizados dentários

a elevadas temperaturas
\end{abstract}

Comportamento dos materiais a elevadas temperaturas

A relação do dente in situ na cavidade oral

\section{Ana Corte-Real \\ Carina Oliveira




\section{RESUMO:}

Existem situações forenses envolvendo exposição a altas temperaturas, nomeadamente por ação de chamas, em que ocorre uma significativa destruição corporal do cadáver. Nestes casos podem subsistir restos dentários ou material de restauração dentário desalojados do osso alveolar e eventualmente dispersos pelo local do evento. A caracterização dos tecidos mineralizados e dos materiais dentários torna-se particularmente relevante nestes casos, na medida em que poderá permitir até o estabelecimento de uma correlação com a temperatura de exposição a que esteve sujeito o cadáver. Em situações extremas de temperatura elevada, a identificação dentária, per si, pode tornar-se impossível, principalmente quando ocorre uma completa destruição dos dentes ou quando os registos clínicos ante mortem são inexistentes. Os molares, por serem geralmente os dentes de menor contacto com o fogo (quer pela protrusão lingual, quer pela contração dos músculos da face e pescoço), são os que permanecem menos alterados, devendo preferencialmente proceder-se à análise da sua raíz, tendo em conta a sua excelência em termos de preservação.

\section{PALAVRAS-CHAVE:}

temperatura de exposição, identificação cadavérica, carbonização, tecidos mineralizados, materiais dentários.

\section{ABSTRACT:}

In forensic situations involving exposure to high temperatures, in particular by the action of fire, a significant destruction of the cadaver occurs. In these cases there may be dental remains or tooth restoration materials displaced from the alveolar bone, and eventually scattered in the site of the traumatic event. The characterization of the mineralized tissues and dental restoration materials becomes particularly important in these cases, as it correlates with the temperature to which the corpse was exposed. In extreme situations of high temperature dental identification may be impossible, especially when a complete destruction of the tooth occurs or when ante mortem clinical records are nonexistent. The molar teeth generally have less contact with fire (either by tongue protrusion or by contraction of face and neck muscles) remaining less altered. Molars roots should be preferred to proceed to analysis, regarding its excellence in terms of preservation.

\section{KEYWORDS:}

exposure temperature, cadaverous identification, carbonization, mineralized tissues, dental materials. 


\section{III.1. INTRODUÇÃO}

Os dentes são órgãos que resistem, in situ, a altas temperaturas (até $400^{\circ} \mathrm{C}$ ) [1-5]. São por isso considerados elementos identificativos de eleição em situações de exposição do corpo humano a temperaturas elevadas. Esta elevada resistência deve-se ao tecido mineralizado das estruturas dentárias, bem como ao facto destas se encontrarem protegidas pelo osso envolvente (mandíbula e maxilar), músculos e tecidos moles da face [1].

O estado que o dente apresenta quando exposto a altas temperaturas está intimamente relacionado com a temperatura alcançada, as condições ambientais (abertas ou fechadas), a natureza do comburente, a duração da combustão e a utilização, ou não, de produtos de extinção.

\section{III.2. ALTAS TEMPERATURAS}

A reação (química) exotérmica entre uma substância orgânica suscetível de oxidação (combustível) e um gás comburente (usualmente o oxigénio) com a libertação de energia sob a forma de calor, é designada por combustão ou queima [1]. Quando este processo é muito exotérmico resulta numa mistura de gases incandescentes (chama) e designa-se por fogo [1]. A combustão é distinta do efeito de estufa, em que o calor é acumulado no corpo, originando uma temperatura superior no interior deste relativamente ao seu redor.

Não obstante o fogo ter sido sempre um elemento fundamental para sobrevivência do ser humano e para o desenvolvimento da humanidade, a verdade é que tem de igual modo um enorme potencial destrutivo. Quando o fogo não é controlado, pode ocorrer um incêndio.

Cada incêndio tem características próprias; pode ser rápido e violento (atingindo rapidamente temperaturas elevadas), ou violento mas de longa duração. As temperaturas atingidas num incêndio variam em função das circunstâncias em que ocorre e do local onde ocorre, sendo o comburente limitado em ambientes fechados (ex. fornos, interior de um veículo, edifícios incendiados), e decorrendo em ambientes abertos (ex. ar livre) da limitação de combustível existente. A intensidade da temperatura atingida depende da natureza do agente oxidante e do seu grau (violência) de oxidação. A ação dos produtos anti-incêndios interferirá, obviamente, na duração da combustão.

O local onde ocorre o incêndio pode ser considerado um critério de caracterização. Um incêndio florestal pode atingir temperaturas entre os $280^{\circ} \mathrm{C}$ e os $400^{\circ} \mathrm{C}$, dependendo da quantidade e tipo de material combustível e das condições de humidade do ar, e podendo até atingir violentamente os $1200^{\circ} \mathrm{C}$ durante um período máximo de 5 minutos [1-5]. Já um fogo numa habitação ou o fogo doméstico, ascende lentamente a temperaturas entre os $650^{\circ} \mathrm{C}$ e $700^{\circ} \mathrm{C}$, com pouca duração do pico máximo e rápida difusão para as áreas vizinhas até à exaustão de todo o comburente [6]. Os incêndios com combustíveis químicos, geralmente de etiologia não natural, como os que ocorrem em viaturas automóveis e aviões, são do tipo violento e atingem milhares de graus quando é elevada a quantidade de combustível existente [1]. 


\section{III.3. ASPETOS HISTÓRICOS DA IDENTIFICAÇÃO DE CADÁVERES E/OU RESTOS BIOLÓGICOS QUEIMADOS}

O primeiro caso de identificação, pelo estudo do sistema estomatognático, foi relatado por Oscar Amoedo, em 1897. Tratou-se de situação decorrente de incêndio, em Paris, da qual resultaram 30 corpos queimados, sem possibilidade de reconhecimento visual ou datiloscópico, tendo a identificação sido obtida com recurso aos odontogramas das vítimas [7].

Também através de estudo comparativo entre os odontogramas post mortem e os registos clínicos e radiográficos existentes do período ante mortem, foi possível a identificação dos cadáveres de Adolfo Hitler (A.H.) e Eva Braun Hitler (E.H.), depois de terem sido queimados. Em relação a A.H. foi possível uma correspondência positiva em 26 evidências, destacando-se a presença de uma prótese parcial fixa anterior na arcada superior e de uma prótese parcial fixa na arcada inferior, bem como restaurações em liga de ouro, porcelana e amálgama, tratamentos endodônticos e registos periodontais nos dentes anteriores inferiores. A identificação de E.H. compreendeu o estudo de uma prótese parcial fixa no quarto quadrante (metade direita da arcada dentária inferior), restaurações em liga de ouro e porcelana, e uma restauração distal do prémolar superior esquerdo com apoio por prótese parcial fixa [7].

A literatura contempla múltiplas descrições do papel determinante da Medicina Dentária na identificação de cadáveres carbonizados. Entre elas estão situações tragicamente célebres, como o Holocausto do Palácio da Justiça da Colômbia, em 1985, ou ainda, neste mesmo país, a identificação dos cadáveres carbonizados no contexto de acidente aéreo da Avianca, em 1989 [7].

Ao longo dos anos foram desenvolvidos estudos do comportamento dos tecidos dentários ao aumento da temperatura e que tiveram por objetivo diferenciar as características estruturais do esmalte [2-6]. Através de um estudo histológico, Myer e colaboradores verificaram, em 1999, que aos $600^{\circ} \mathrm{C}$ a dentina é o tecido dentário que melhor define a temperatura de exposição [8]. Outros autores, como Merlati e colaboradores, desenvolveram estudos procurando avaliar o comportamento dos dentes restaurados ao aumento da temperatura [3].

\section{4. O CORPO QUEIMADO VERSUS CARBONIZADO - LESÕES PERI MORTEM - O EXAME}

Em virtude da grande variabilidade de parâmetros que influenciam a caracterização de um incêndio, não ocorrem duas situações idênticas. Consoante as características peculiares de cada incêndio, assim resultam queimaduras, mais ou menos extensas e profundas, com destruição parcial ou total do corpo [7,9]. Utiliza-se habitualmente a classificação clássica de Dupuytren, que estabelece graus distintos consoante a intensidade lesional na região queimada. As menos intensas, são assim, as queimaduras de $1^{\circ} \mathrm{grau}$, caracterizadas por eritema cutâneo e hiperémia da pele devido à vasodilatação capilar, endurecimento da pele, prurido, dor e irritação dos terminais nervosos. Nas queimaduras de $2^{\circ} \mathrm{grau}$ 
observam-se vesículas ou flitenas por liquefação do corpo mucoso da derme, com libertação de histamina e plasma que enchem as vesículas e infiltram os tecidos vizinhos, conferindo-lhes um aspeto edemaciado. Nas queimaduras de $3^{\circ} \mathrm{grau}$, as lesões têm um aspeto esbranquiçado e ocorre destruição parcial da pele, dando origem a escaras que envolvem a derme e o tecido subconjuntivo subjacente. Por último, as queimaduras de $4^{\circ} \mathrm{grau}$ são caracterizadas por uma total destruição dos tecidos, atingindo a carbonização [10].

A carbonização ocorre, pois, quando a ação da chama ou matérias inflamadas se mantêm sobre o corpo durante tempo suficiente (figs. III.1), podendo os restos cadavéricos ficarem reduzidos a pó [10]. Contudo, a combustão pode não ser diretamente responsável pela morte do indivíduo exposto ao incêndio [10]. A morte resulta frequentemente da inalação de gases tóxicos (morte por asfixia), de patologia cardíaca, de politraumatismos e, numa pequena percentagem, das queimaduras. Um mecanismo não exclui os outros, podendo concorrer vários simultaneamente para a morte.

$\mathrm{Na}$ carbonização verifica-se um efeito geral de condensação dos tecidos e, consequentemente, uma redução do volume dos órgãos e membros, por vezes até da totalidade do cadáver. Segundo a American Society of Forensic Odontology, a redução do volume corporal total decorre em 1 a 1,5 horas, a temperaturas entre $870^{\circ} \mathrm{C}$ a $980^{\circ} \mathrm{C}$, dependendo da idade do indivíduo (criança ou adulto), de variações da descalcificação óssea ou da densidade de massa [11]. A destruição corporal decorrente de um processo de carbonização pode colocar sérias dificuldades na identificação cadavérica. A severidade da lesão depende da temperatura alcançada num incêndio, da sua duração, bem como da idade do indivíduo e da zona corporal atingida [11]. A utilização de combustível líquido sobre áreas corporais específicas pode resultar numa severidade desproporcional das lesões entre os diversos segmentos corporais.

Nos casos de carbonização, o cadáver adota a atitude típida de «pugilista», em consequência de um fenómeno de contratura muscular devido à ação do calor, com predomínio da musculatura flexora sobre a extensora. A superfície externa do corpo assume uma cor negra, com pele seca, apergaminhada (desidratada) e dura. Ocorre chamuscamento e, por vezes, desaparecimento dos pelos e cabelos (figs. III.1). Se a carbonização for suficientemente profunda, as cavidades craniana, torácica e abdominal podem chegar a abrir-se, com saída de vísceras ou a destruição destas pela ação do calor (fig. III.1D). As superficies de corte são regulares e limpas, sem reação vital. Nestes casos, nem sempre a superfície corporal está totalmente carbonizada ou queimada, podendo ser poupadas áreas corporais protegidas pelo vestuário ou aquelas que não tiveram contactado diretamente com as chamas. Podem também ocorrer amputações espontâneas dos membros, geralmente ao nível da transição dos terços superior e médio. Por último, a córnea pode adquirir uma coloração que simula uma íris azul, situação suscetível de criar dificuldades no processo de identificação cadavérica.

No processo de identificação deste tipo de vítimas deve adotar-se uma metodologia adequada $[10,11]$, iniciada pela realização de exames radiográficos, seguida por um detalhado exame do hábito externo e do hábito interno. 

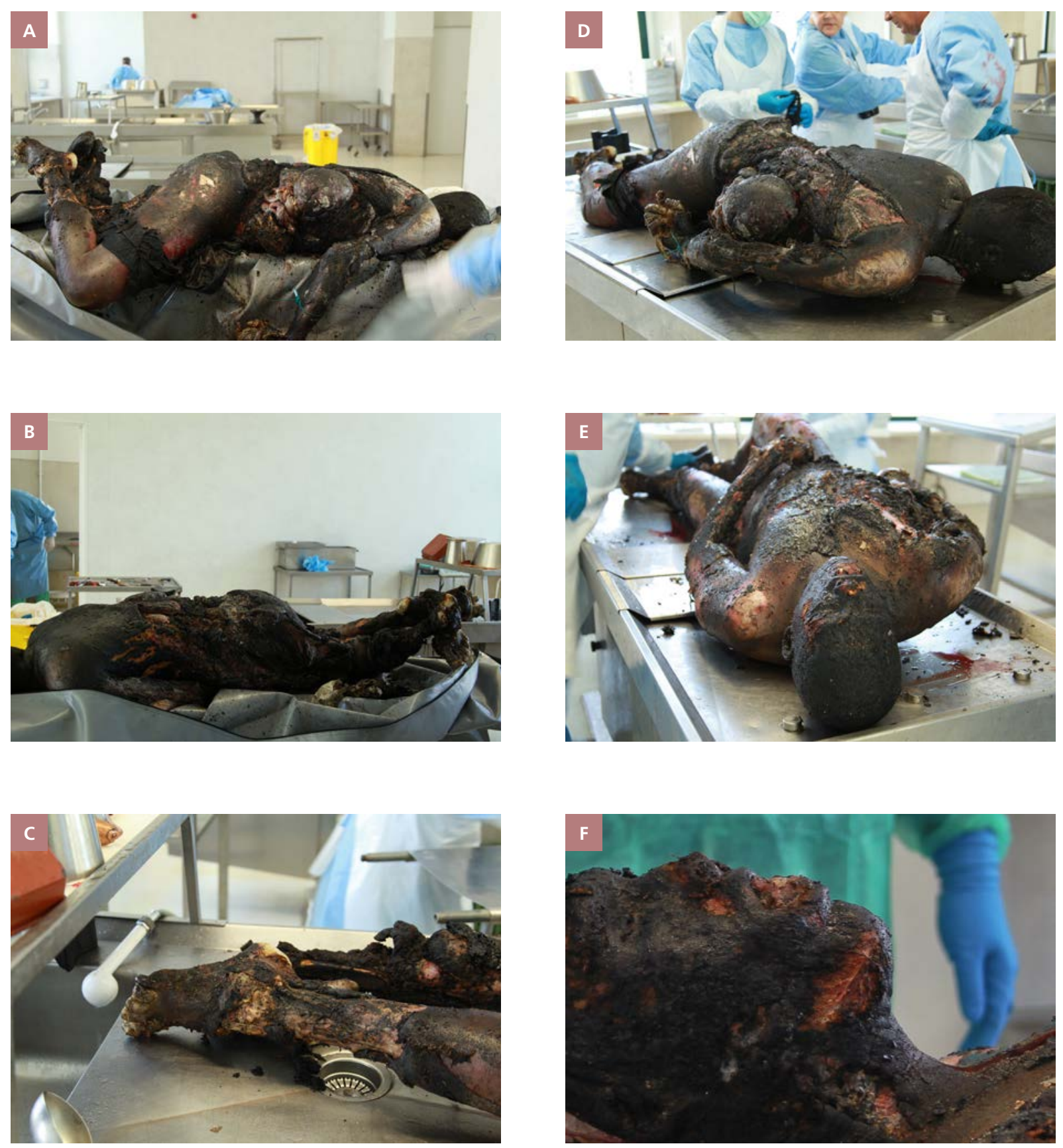

Figuras III.1 (A,B,C,D,E e F). Morte em situação de fogo doméstico. (A) Vista lateral direita do cadáver. (B) Vista lateral esquerda do cadáver. (C) Destacamento epidérmico no pé direito. (D) Cadáver em decúbito ventral, com expulsão dos órgãos abdominais da respetiva cavidade. (E) Vista superior do cadáver. (F) Vista lateral direita da face, evidenciando a boca aberta por retração dos lábios. Cortesia do INMLCF, I.P 2013. 
O exame do hábito externo corresponde a um procedimento não invasivo, com observação dos dentes visíveis. No que se refere à face e consoante o grau de exposição à chama, atenuam-se ou desaparecem os sulcos nasogenianos, pode ocorrer uma redução do nariz com desaparecimento da sua extremidade, encerram-se as pálpebras que se apresentam desprovidas de pêlos (pestanas e sobrancelhas) e a boca pode encontrar-se fechada ou «semi-aberta» pela retração labial, permitindo a visualização dos dentes anteriores (ou apenas dos superiores se a língua estiver entreposta entre ambas as arcadas dentárias), que ficam móveis ou quebradiços (figs. III.1F e III.2)

O fogo, ao produzir lesões teciduais irreversíveis no sistema estomatognático, reduz a quantidade de informação útil disponível para identificação.

Em situações de corpos expostos a elevadas temperaturas, estaremos a lidar implicitamente com cadáveres desfigurados ou fragmentados pela violência do traumatismo sofrido. Nestes casos, a redução do volume de massa corporal pode também complicar a interpretação no que se refere à idade do cadáver, podendo sugerir corrresponder a um indivíduo muito mais jovem. Por outro lado e no âmbito de uma investigação forense, é fundamental que nestes casos se proceda ao diagnóstico diferencial entre queimaduras ante e post mortem.

O exame do hábito interno, por sua vez, corresponde a um procedimento invasivo e inicia-se com a abertura do crânio. Neste tipo de situações, o tecido encefálico atinge por vezes temperaturas extremas [1], podendo ocorrer artefactos, tais como, fratura da calote craniana e hemorragia epidural, na medida em que a retração meníngea

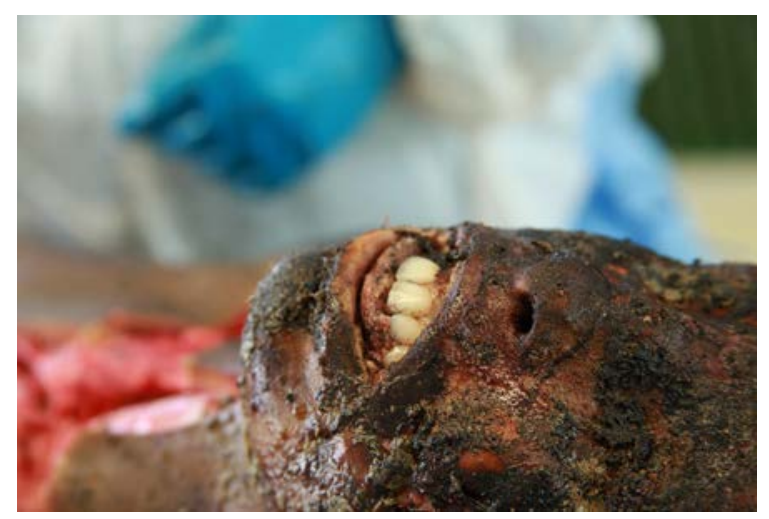

Figura III.2 - Protrusão da língua com revestimento dos dentes anteriores da arcada inferior em cadáver carbonizado. Cortesia do INMLCF, I.P 2013.

proporcionará a acumulação de sangue entre a dura-máter e o osso (figs. III.3) [10].

O exame da cavidade oral deve ser complementado com registo fotográfico e radiográfico.

Nos casos de exposição a elevadas temperaturas, os dentes podem apresentar-se fragmentados ou desalojados do osso alveolar, e estarem até dispersos pela cavidade oral.

Nas situações supracitadas, podem ser utilizadas as normas de registo da Interpol indicadas nos desastres de massa $[12,13]$. Devem ser registadas todas as características dentárias, de modo a ser possível efetuar um estudo comparativo com os registos dentários ante mortem obtidos.

Uma vez que tanto a fisionomia do indivíduo, como a datiloscopia, não são exames úteis nestas situações no processo de identificação [12], 

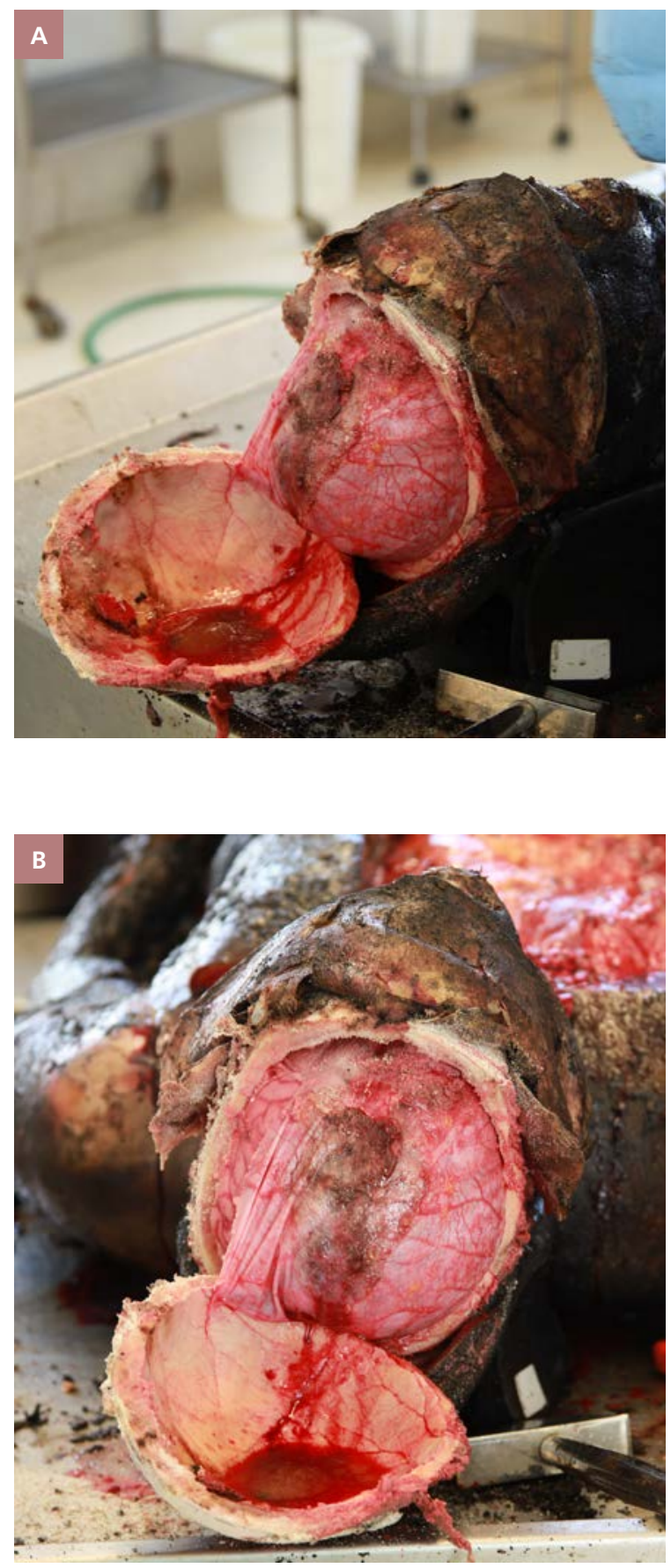

Figuras III.3 (A e B) - Visualização da hemorragia epidural após abertura da calote craniana em cadáver carbonizado. Cortesia do INMLCF, I.P 2013. deve ser elaborado um odontograma detalhado, conforme mencionado no Capítulo I, com registo das restaurações intactas ou dispersas, os dentes ausentes (extraídos ou avulsionados), as próteses fixas (individualizadas ou em grupo, pontes) e/ ou as próteses removíveis. Devem igualmente ser registados eventuais distúrbios da erupção dentária, tipos de maloclusão (classes dentárias de Angle, mordida profunda, mordida cruzada).

Quanto ao processo de identificação, a complementaridade dos métodos dentários e radiográficos alcança maior sucesso em indivíduos com idade inferior a 20 anos, na medida em que, nesta faixa etária, existe geralmente um maior número de caracteres individualizantes [12].

Devem ser efetuados exames radiográficos post mortem, utilizando as técnicas de registo periapical e extraoral (ortopantomografia) [14-18].

\section{III.5. COMPORTAMENTO DOS TECIDOS MINERALIZADOS DENTÁRIOS A ELEVADAS TEMPERATURAS}

O estudo do comportamento dos tecidos dentários perante o aumento da temperatura a que são expostos realiza-se numa perspetiva morfológica. Segundo Merlati, Savio e Espina, os tecidos dentários podem sofrer alterações estruturais (figs. III.4) distintas num mesmo indivíduo [2-6].

A descrição macroscópica dos tecidos dentários inclui as alterações de cor, textura e morfologia [19]. As alterações colorimétricas do dente podem englobar o castanho, o preto, 

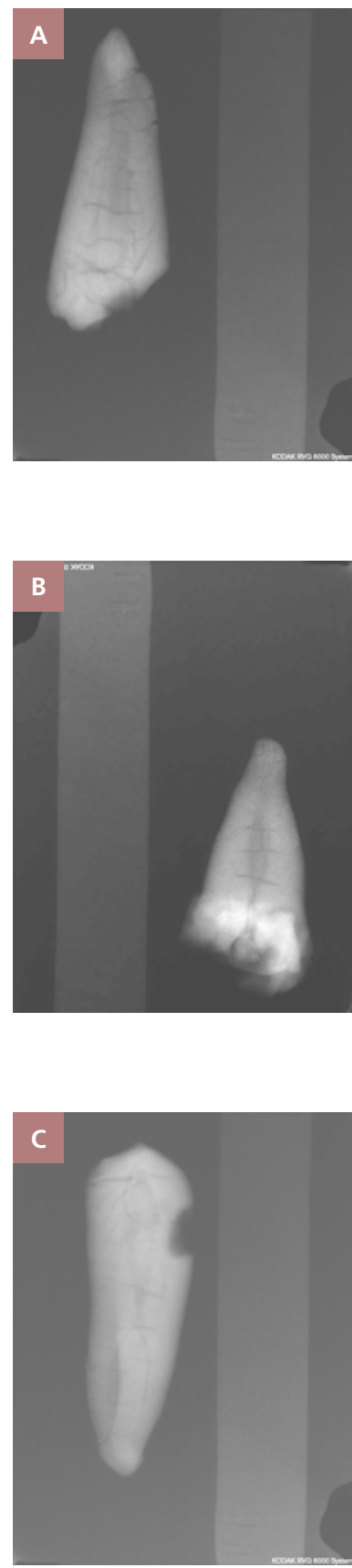

Figuras III.4 (A, B e C) - Imagens radiográficas de peças dentárias de um indivíduo do género feminino, com cerca de 70 anos de idade, vítima de acidente (fogo doméstico).

(A) Canino superior; (B) Segundo molar superior com vestígios de restauração a amálgama; (C) Pré-molar inferior. o cinzento e o branco, este último na temperatura mais elevada (tab. III.1). As alterações de textura compreendem a rugosidade de superfície com a descontinuidade das linhas anatómicas e as alterações de contorno do dente e das respetivas restaurações. As alterações morfológicas compreendem a descontinuidade entre os tecidos mineralizados (culminando na perda do esmalte e na rugosidade da dentina) e a perda do tecido ósseo alveolar (que expõe o cemento, e que, assim como a dentina, adquire uma textura irregular e rugosa) [14].

Para melhor organização de conteúdo serão abordados separadamente cada tecido mineralizado.

O esmalte sofre alterações macroscópicas e microscópicas quando exposto a elevadas temperaturas (tab. III.1).

Segundo Ferreira [20], em dentes jovens e expostos a baixas temperaturas, observa-se microscopicamente, uma separação entre o esmalte e a dentina, além de pequenas fissuras na dentina (tab. III.2). Nos dentes adultos, expostos a uma intensidade idêntica no que se refere à temperatura, ocorre uma separação do esmalte e da dentina, ao nível da junção amelodentinária [20]. Por outro lado, quando os dentes jovens são expostos a temperaturas elevadas, surge uma zona periférica negra e um pequeno número de trajetórias de fraturas centrípetas a nível do esmalte. Nestes casos, é ainda possível identificar estruturas na dentina e no cemento, tais como as linhas de aposição deste tecido e áreas de completa separação entre a dentina e o cemento. Nos dentes adultos expostos a 
Tabela III.1 - Alterações radiográficas do dente não restaurado e sujeito à ação da temperatura (stress térmico) [4,5].

\begin{tabular}{|c|c|c|}
\hline Temperatura ${ }^{\circ} \mathrm{C}$ & Coroa & Raíz \\
\hline $200^{\circ} \mathrm{C}$ & Original & Original \\
\hline $400^{\circ} \mathrm{C}$ & Fissuras entre esmalte e dentina & Original \\
\hline $600^{\circ} \mathrm{C}$ & $\begin{array}{c}\text { Separação do esmalte } \\
\text { Fissuras na dentina }\end{array}$ & Fissuras na dentina \\
\hline $800^{\circ} \mathrm{C}$ & $\begin{array}{c}\text { Total separação do esmalte } \\
\text { Fraturas na dentina }\end{array}$ & Frandes fraturas na dentina \\
\hline $1000^{\circ} \mathrm{C}$ & Reduzida a fragmentos & Grandes fraturas na dentina \\
\hline $1100^{\circ} \mathrm{C}$ & Inexistente & Granter \\
\hline
\end{tabular}

Tabela III.2 - Alterações microscópicas do esmalte, in vitro, quando exposto a determinadas temperaturas, durante 60 minutos [3, 20].

\begin{tabular}{|c|c|c|}
\hline Temperatura ${ }^{\circ} \mathrm{C}$ & Observações macroscópicas & Observaçães microscópicas \\
\hline $20-185^{\circ} \mathrm{C}$ & Alterações colorimétricas & Normal e inalterado \\
$185-285^{\circ} \mathrm{C}$ & Castanho a cinzento escuro com & $\begin{array}{c}\text { Surgem irregularidades na superfície } \\
\text { pequenas fissuras superficiais } \\
\text { mas preservadas arredondadas na superfície }\end{array}$ \\
\hline $285-440^{\circ} \mathrm{C}$ & Separação total do esmalte & Separação união amelontentinária cervical \\
\hline $450^{\circ} \mathrm{C}[21]$ & Fragmentaçãa \\
\hline $600^{\circ} \mathrm{C}$ & Branco total em partículas & $\begin{array}{c}\text { Dividido por rede de fendas; placas } \\
\text { multiangulares e superfície irreconhecível }\end{array}$ \\
\hline $900^{\circ} \mathrm{C}$ & Fusão dos sais inorgânicos \\
\hline
\end{tabular}

Tabela III.3 - O comportamento de materiais dentários a elevadas temperaturas: alterações dimensionais e da forma [5,19,21-25].

\begin{tabular}{|c|c|c|c|c|c|}
\hline Localização & & Tipos & $600^{\circ} \mathrm{C}\left(112^{\circ} \mathrm{F}\right)$ & $1000^{\circ} \mathrm{C}\left(1832^{\circ} \mathrm{F}\right)$ & $1100^{\circ} \mathrm{C}\left(2012^{\circ} \mathrm{F}\right)$ \\
\hline \multirow{3}{*}{ Coronários } & Amálg & $\begin{array}{l}\text { ha - Dispersalloy } \\
\text { ntsply, USA) }\end{array}$ & \multicolumn{2}{|c|}{ Original } & Alterada \\
\hline & \multicolumn{2}{|r|}{ Cerâmica } & \multicolumn{3}{|c|}{ Original } \\
\hline & Compósito & Herculite $^{\circledR}$ (Kerr, USA) & Original & \multicolumn{2}{|c|}{ Alterada } \\
\hline \multirow[t]{2}{*}{ Radiculares } & \multicolumn{2}{|c|}{ Endometasona/guta-percha } & $\begin{array}{l}\text { Radiopacidade } \\
\text { menos regular }\end{array}$ & \multicolumn{2}{|c|}{$\begin{array}{l}\text { Ligeiramente alterada } \\
\text { (muitas zonas radiotransparentes } \\
\text { em «favo de mel») }\end{array}$} \\
\hline & \multicolumn{2}{|c|}{ Implantes endoósseos } & \multicolumn{3}{|c|}{ Original } \\
\hline
\end{tabular}


elevadas temperaturas verifica-se que: a área negra é menos densa que a dos jovens; a direção das fissuras coronárias segue a orientação dos prismas dentinários; o cemento é bem delimitado em relação à dentina subjacente; as linhas incrementais do cemento podem ser distinguidas; as fissuras seguem as linhas de aposição do cemento; a dentina perde a sua estrutura tubular e verifica-se a presença de amplas e profundas fissuras na dentina radicular [20].

De igual modo, a dentina e o cemento, quando expostas a altas temperaturas, sofrem alterações macro e microscópicas. Ainda neste contexto, a porção radicular do dente permanece mais resistente, e a sua caracterização permite estimar uma temperatura provável de exposição, bem como estudar a morfologia radicular e materiais endodônticos utilizados na reabilitação [21].

\section{III.6. COMPORTAMENTO DOS MATERIAIS A ELEVADAS TEMPERATURAS}

O comportamento dos materiais dentários, restauradores e protéticos sujeitos a elevadas temperaturas, deve ser descrito em termos morfológicos e radiológicos (tab. III.3). Deve ser estudado o valor, o tempo de exposição e a curva de variação da temperatura.

As cerâmicas dentárias apresentam-se como compostos inorgânicos de elementos metálicos e não metálicos: sílica $\left(\mathrm{SiO}_{2}\right)$, feldspato com pigmentos, opacificadores e fundentes. É um critério de agrupamento dos sistemas cerâmicos à temperatura de fusão. A sílica apresenta uma temperatura de fusão alta (cerca de $1700^{\circ} \mathrm{C}$ ). As cerâmicas, com todos os seus constituintes, podem ser divididas quanto à temperatura média de fusão: alta fusão $\left(1290^{\circ} \mathrm{C}-1370^{\circ} \mathrm{C}\right)$; média fusão $\left(1090^{\circ} \mathrm{C}-1260^{\circ} \mathrm{C}\right)$; baixa fusão $\left(860^{\circ} \mathrm{C}-1070^{\circ} \mathrm{C}\right)$ e ultra-baixa fusão (menos de $850^{\circ} \mathrm{C}$ ) $[21,22]$. Destacam-se, atualmente, os sistemas de zircónia (ex.sistemas In-Ceram $®$ Zircónia e Procera $®$ AllZircon) em dentes anteriores e posteriores, por não apresentarem uma matriz vitrosa e serem mais resistentes à formação de fissuras, à degradação química a altas temperaturas e à pressão $[23,24]$.

No que se refere aos implantes, os de titanium apresentam um ponto de fusão próximo dos $1650^{\circ} \mathrm{C}$, enquanto os de zircónia apresentam um ponto de fusão acima dos $1850^{\circ} \mathrm{C}$. Estas propriedades físicas com um ponto de fusão elevado podem potencialmente contribuir para a identificação das vítimas [15,23].

As alterações na amálgama compreendem, sequencialmente, a perda de brilho e descoloração, a perda de selamento marginal e, por fim, devido à dissociação das ligas metálicas e perda de mercúrio, a restauração perde a sua forma original, adquirindo uma forma globular [5].

Na relação do comportamento das resinas e dos componentes com ionómero de vidro a temperaturas elevadas, destaca-se o ponto de fusão dos seus constituintes e a volatilização da sua componente orgânica com a consequente perda de peso.

As resinas desaparecem a temperaturas entre $500^{\circ} \mathrm{C} \mathrm{e} 700^{\circ} \mathrm{C}$; segundo Robinson, o material microparticulado (Silux ${ }^{\circledR}$ plus ${ }^{\mathrm{TM}}$ ) tem um menor conteúdo inorgânico (58\%), o material híbrido com partículas médias (Herculite ${ }^{\circledR} \mathrm{xrv}^{\mathrm{TM}}$ ) tem um conteúdo médio (74\%) e o material híbrido 
Tabela III.4 - O comportamento de materiais protéticos a elevadas temperaturas: alterações da forma [23]. As ligas metálocas resultam da mistura de dois ou mais elementos, sendo pelo menos um deles metal. A variedade de metais disponíveis para a fundição possibilita a correspondente diversidade de composições. Podemos destacar os seguintes pontos de fusão: ouro (1064 ${ }^{\circ} \mathrm{C}$ ); prata $\left(906^{\circ} \mathrm{C}\right)$; paládio $\left(1554^{\circ} \mathrm{C}\right)$; níquel $\left(1455^{\circ} \mathrm{C}\right)$; cobalto $\left(1495^{\circ} \mathrm{C}\right)$; crómio $\left(1907^{\circ} \mathrm{C}\right)$ e aluminio $\left(660^{\circ} \mathrm{C}\right)$.

\begin{tabular}{|c|c|c|c|c|}
\hline Tipos de Próteses & $600^{\circ} \mathrm{C}\left(112^{\circ} \mathrm{F}\right)$ & $1000^{\circ} \mathrm{C}\left(1832^{\circ} \mathrm{F}\right)$ & $1100^{\circ} \mathrm{C}\left(\mathbf{2 0 1 2}^{\circ} \mathrm{F}\right)$ & $1500^{\circ} \mathrm{C}$ \\
\hline Acrílicas & Original & Alterada & Alterada & Alterada \\
\hline $\begin{array}{c}\text { Esqueléticas } \\
\text { (cromo-níquel) }\end{array}$ & Original & Original & Original & Alterada \\
\hline Ligas nobres & \multicolumn{2}{|c|}{ Consoante o ponto de fusão dos elementos constituintes } \\
\hline Cerâmicas & Original & Original & Original & Alterada \\
\hline
\end{tabular}

macroparticulado (occlusion) tem uma percentagem maior ( $87 \%$ ) e tende a decompor-se a uma temperatura menor $[26,27]$. Segundo Bursh e colaboradores, as várias temperaturas de exposição até à de fusão não provocam alterações bioquímicas na composição das resinas [19]. As alterações colorimétricas das resinas acompanham-se de alterações do dente para as mesmas temperaturas [19].

Os ionómeros de vidro adquirem um aspeto leitoso entre $800^{\circ} \mathrm{C}$ e $1000^{\circ} \mathrm{C}$ [26] e a decomposição térmica de materiais que os contêm é notavelmente distinta daqueles constituídos por resina.
Em termos genéricos, assinale-se que as próteses acrílicas removíveis, aos $400^{\circ} \mathrm{C}$ sofrem alterações mínimas da superfície e aos $600^{\circ} \mathrm{C}$ desaparecem na sua totalidade. As próteses fixas em metalorresina sofrem alterações aos $400^{\circ} \mathrm{C}$ com perda parcial do acrílico, aos $600^{\circ} \mathrm{C}$ apresentam uma perda significante de substância, ocorrendo aos $800^{\circ} \mathrm{C}$ alterações estéticas na coloração do metal por oxidação e existindo apenas a estrutura metálica aos $1000^{\circ} \mathrm{C} / 1100^{\circ} \mathrm{C}$. Nas próteses fixas metalocerâmicas podem surgir a $1000^{\circ} \mathrm{C} / 1100^{\circ} \mathrm{C}$ alterações na textura da cerâmica (tab. III.4). 


\section{III.7. A RELAÇÃO DO DENTE IN SITU NA CAVIDADE ORAL}

Nas temperaturas elevadas ocorre uma contração dos músculos da cavidade oral que, por sua vez, provoca a exposição da região anterior dessa cavidade à ação da chama [14]. Após esta fase inicial de contração, há uma expulsão de gases do trato digestivo, o que promove uma protrusão da língua e consequente ocultação dos dentes inferiores [8]. Geralmente os dentes permanecem na sua posição original, ou seja, alojados nos respetivos alvéolos, podendo os maxilares apresentar uma fratura mediana [14]. A porção coronária é a primeira porção dentária a ser exposta às temperaturas elevadas, seguida da porção radicular quando o tecido ósseo é consumido pela ação da chama [12]. Num mesmo indivíduo podem ocorrer alterações estruturais distintas, consoante a localização da estrutura dentária ou da sua reabilitação na cavidade oral, sendo que os dentes anteriores podem caracterizar, de alguma forma, a ação da elevada temperatura, o que já não ocorre com os dentes posteriores, que se encontram mais protegidos da ação da chama e que, ao permanecerem inalterados, não permitem caracterizar o ambiente a que o cadáver esteve exposto $[6,14]$.

Quando expostos a altas temperaturas, os dentes dos indivíduos jovens podem apresentar fissuras e fraturas segundo o eixo sagital, com diversas ramificações laterais, enquanto nos dentes dos indivíduos idosos, o padrão característico das fissuras e das fraturas é reticulado, ou seja, há uma associação de linhas longitudinais e transversais [8].

\section{III.8. REFERÊNCIAS}

[1] Raimundo, A., Figueiredo, C. (2006). Human thermophysiological response to high intensity radiation fluwes near a forest fire line. $V$ International Conference on Forest Fire Research DX Viegas, pp.S145.1-S145.36.

[2] Merlati, G., Danesino, P., Savio, C. e col. (2002). Observations on dental prostheses and restorations subjected to high temperatures: experimental studies to aid identification processes. J For Odontostomatol, Dec, 20(2), pp. 17-24.

[3] Merlati, G., Savlo, C., Danesino, P. (2004). Further study of restored and un-restored teeth subjected to high temperatures. J For Odontostomatol, pp. 22:34-39.

[4] Savlo, C., Merlati, G., Danesino, P. e col. (2006). Radiographic evaluation of teeth subjected to high temperatures: experimental study to aid identification process. For Sci Int, 158, pp. 108-116.

[5] Patidar, K.A., Parwani, R., Wanjari, S. (2010). Effects of high temperature on different restorations in forensic identification: Dental samples and mandible. J For Dent Sci, Jan-Jun, 2(1), pp. 37-43.

[6] Espina, A., Barrios, F., Ortega, A. e col. (2004). Cambios estructurales en los tejidos dentales duros por acción del fuego directo, según edad cronológica. Ciencia Odontológica, 1(1), pp. 38-51.

[7] Stimson, P.G. (1997). Forensic Dentistry CRC Press.

[8] Myers, S., Willians, J., Hodges, J. (1999). Effects of extreme heat on teeth with implications for histologic processing. J For Sci. 44(4), pp. 805-809.

[9] Taylor, W., Lyons, T. (2002). Forensic Odontology lessons: multishooting incident at Port Arthur, Tasmania. For Sci Int, 130, pp.174-182.

[10] Saavedra, L.A. (2006). Patologia forense nas mortes com evidente ação do fogo. Saúde, Ética \& Justiça, 11(1/2), pp. 1-7.

[11] Bitemark Methodology Guidelines. (2013). American Board of Forensic Odontology, Inc. Diplomates Reference Manual, pp. 109-117.

[12] Valenzuela, A., Martin-de-las-Heras, S., Marques, T. e col. (2000). The application of dental methods of identification to human burn victims in a mass disaster. Int J Legal Med, 113, pp. 236-239. 
[13] Disasters Victim identification Guide Interpol. (2009). Disponivel em: http://www.interpol.int.

[14] Delattre, V.F. (2000). Burned beyond recognition: Systematic approach to the dental identification of charred human remains. J For Sci, 45(3), pp. 589-596.

[15] Andersen, L., Juhl, M., Solheim, T. e col. (1995). Odontological Identification of Fire Victims-Potentialities and Limitations. Int J Legal Med, 107, pp. 229-234.

[15] Berketa, J., James, H., Marino, V. (2011). Dental implant changes following incineration. For Sci Int. April, (27)1, pp. 50-54.

[16] Berketa, J., James, H., Marino, V. (2010). Survival of batch numbers within dental implants following incineration as an aid to identification. J For Odontostomatol, 28(1), pp.1-4.

[18] Bush, M., Miller, R. (2011). The crash of Colgan Air flight 3407: advanced techniques in victim identification. J Am Dent Assoc., Dec, 142(12), pp.1352-1356.

[19] Muller, M., Berytrand, M.F., Quatrehomme, G. e col. (1998). Macroscopic and microscopic aspects of incinerated teeth. J For Odontostomatol, 16, pp.1-7.

[20] Ferreira, J.L., Ferreira, A.E., Ortega, A.I. (2008). Methods for the analysis of hard dental tissues exposed to high temperatures. For Sci International, 178, pp.119-124.
[21] Bush, M.A., Bush, P.J., Prutsman-Pfeifer, J. e col. (2007). Identification through $\mathrm{X}$-Ray fluorescence analysis of dental restorative resin materials: a comprehensive study of noncremated, cremated and processed-cremated individuals. J For Sci, 52, pp.157-165.

[22] Robinson, F.G., Rueggeberg, F.A., Lockwood, P.E. (1998). Thermal stability of direct dental esthetic restorative materials at elevated temperatures. J For Sci, 43(6), pp.1163-1167.

[23] Craig, R. (1993). Restorative Dental Materials. St. Louis: Mosby.

[24] William, J., O’Brien. (2002). (3 $3^{\mathrm{a} e d .) . ~ C a r o l ~ S t r e a m, ~ C a n a d a: ~}$ Quintessence Publishing. Co, Inc, Dental Materials and their Selection.

[25] Bonavilla, J.D., Bush, M.A., Bush, P.J. e col. (2008). Identification of incinerated root canal filling materials after exposure to high heat incineration. J For Sci, Mar, 53, pp. 412-418.

[26] Moya, V., Roldan, B., Sánchez, J.A. (1994). Odontologia legal y forense. Barcelona: Editorial Masson S.A.

[27] Fairgrieve, S.I. (2008). Incineration of Dental Tissues In Forensic Cremation - Recovery and Analysis, CRC Press, (1 ${ }^{\mathrm{a} e d}$.), pp.141-160. 